\title{
Complications of Central Venous Totally Implantable Access Port: Internal Jugular Versus Subclavian Access
}

Pil Young Jung, M.D., Hoon Ryu, M.D., Ph.D., Jae Hung Jung, M.D. , Eunbi Lee, M.D. , Joong Hwan Oh, M.D., Ph.D. , Chun Sung Byun, M.D. , and Il Hwan Park, M.D.

Department of Surgery, ${ }^{*}$ Department of Thoracic and Cardiovascular Surgery, ${ }^{\dagger}$ Department of Anesthesiology, Wonju College of Medicine,

Wonju Severance Christian Hospital, Wonju, Korea

2015 February 30(1):13-17 / http://dx.doi.org/10.4266/kjccm.2015.30.1.13

We found an error in this article. The author's affiliation should be corrected as following:

from "Pil Young Jung, M.D., Hoon Ryu, M.D., Ph.D., Jae Hung Jung, M.D.", Eunbi Lee, M.D.", Joong Hwan Oh, M.D., Ph.D.", Chun Sung Byun, M.D *, and Il Hwan Park, M.D.""

Department of Surgery, "Department of Thoracic and Cardiovascular Surgery, 'Department of Anesthesiology, Wonju College of Medicine, Wonju Severance Christian Hospital, Wonju, Korea"

to "Pil Young Jung, M.D. ${ }^{1}$, Hoon Ryu, M.D., Ph.D. ${ }^{1}$, Jae Hung Jung, M.D. ${ }^{2}$, Eunbi Lee, M.D. ${ }^{3}$, Joong Hwan Oh, M.D., Ph.D. ${ }^{4}$, Chun Sung Byun, M.D. ${ }^{4}$, and Il Hwan Park, M.D. ${ }^{4}$

${ }^{1}$ Department of Surgery, ${ }^{2}$ Department of Urology, ${ }^{3}$ Department of Anesthesiology, ${ }^{4}$ Department of Thoracic and Cardiovascular Surgery, Wonju College of Medicine, Wonju Severance Christian Hospital, Wonju, Korea"

We apologize for any inconvenience that may have caused. 